\title{
REFLEXIÓN DOCUMENTADA SOBRE EL USO DEL ÁRABE Y DE LAS LENGUAS ROMÁNICAS EN LA ESPAÑA DE LOS MORISCOS (sS. XVI-XVII)
}

\author{
Bernard VINCENT \\ École des Hautes Études Sociales (París)
}

\begin{abstract}
"Quien pierde la lengua arábiga pierde su ley" advierte el granadino Aben Daud en una carta que dirige a los musulmanes del Norte de África, cuando la sublevación de los moriscos de las Alpujarras ${ }^{1}$. No se puede destacar mejor la importancia de la conservación de su propia lengua, para una comunidad enfrentada a toda clase de represiones. Se trata de su existencia misma. La lengua es un envite fundamental del enfrentamiento entre la minoría amenazada con perder su identidad y la sociedad dominante que busca asimilarla por todos los medios. Por eso no es extraña la cantidad de disposiciones que tienen por objeto prohibir el uso del árabe por parte de los criptomusulmanes, en la España del siglo XVI.

Hacer un catálogo de esas disposiciones sería probablemente una tarea vana. Algunos recuerdos significativos bastarán para mostrar el carácter permanente de una preocupación rayana con la obsesión. Todos los grandes textos destinados a poner en pie una política de aculturación se detienen en la cuestión lingǘstica. Ya desde los años 20 del siglo XVI, la asamblea reunida en la Capilla Real de Granada en 1526 estipula que "por obviar y remediar los daños e inconvenientes que se siguen de continuar los dichos nuevamente convertidos a hablar arábigo,
\end{abstract}

${ }^{1}$ Luis de Mármol Carvajal, Historia de la rebelión y castigo de los moriscos del reino de Granada, Biblioteca de Autores Españoles, tomo XXI, Madrid, 1946, p. 179. 
mandamos que ninguno de ellos, ni sus hijos, ni otra persona alguna de ellos, no hable de aquí adelante en arábigo, ni se haga escritura alguna en arábigo, y hablen todos la lengua castellana" 2 . Se busca en particular la supresión del árabe en los contratos. Esas y otras medidas fueron diferidas --como es sabido-- a consecuencia de negociaciones apuntaladas con la entrega de cantidades numerarias. Paralelamente, en 1528, los moriscos valencianos intentan apartar la amenaza argumentando que se necesita tiempo para aprender otra lengua. Cuarenta años más tarde, hay una nueva ofensiva. Las Cortes valencianas, en 1564, ordenan hacer quemar todos los libros escritos en lengua árabe ${ }^{3}$. La cédula real del 17 de noviembre de 1566 obliga a los moriscos granadinos a aprender el castellano en un plazo de tres años ${ }^{4}$. De paso, las autoridades enumeran los peligros provocados por la persistencia del árabe: mantenimiento de la fe musulmana, dificultad de la catequesis, ejercicio de prácticas prohibidas. A tenor de textos un poco anteriores al decreto de expulsión de 1609 , los efectos de estas medidas fueron mediocres. El 17 de mayo de 1595, Felipe II pedía que se enseñara el castellano y el valenciano a los criptomusulmanes y que los catecismos fueran redactados en las dos lenguas ${ }^{5}$. La asamblea reunida el 22 de noviembre de 1608, en Valencia, se pregunta por los hipotéticos beneficios de una política coercitiva, antes de aparcarla: "pareció...que tenía grande dificultad o imposibilidad para lo presente..." .

El fracaso es evidente. Parece que los esfuerzos emprendidos en materia de enseñanza y que los avisos y prohibiciones repetidos hayan topado con un muro, en el caso valenciano como en el caso granadino. A la inversa, las comunidades castellanas, inmersas desde hacía siglos en un océano cristiano, no habían podido conservar su lengua. Aquí

${ }^{2}$ Ver el texto en Antonio Gallego y Burín y Alfonso Gámir Sandoval, Los moriscos del reino de Granada según el sínodo de Guadix de 1554, Granada, 1968, p. 202.

${ }^{3}$ Cortes valencianes del reinado de Felipe II, ed. Emilia Salvador, Valencia, 1974 , p. 14.

${ }^{4}$ Archivo General de Simancas (A.G.S.), Registro del Sello, 1566.

5 Pascual Boronat y Barrachina, Los moriscos españoles y su expulsión, Valencia, 1901, tomo I, p. 660.

${ }^{6}$ lbid., tomo II, p. 135. 
también los testimonios son abundantes. $\mathrm{Y}$ actualmente ya es opinión generalmente admitida que los moriscos aragoneses no conocían el árabe ${ }^{7}$. Míkel de Epalza llega a pensar que los cristianos nuevos de la margen derecha del Ebro nunca habían llegado a ser arabizados del todo $^{8}$. Así es cómo una pareja granadina-valenciana se opondría, desde el punto de vista lingüístico, a una pareja castellano-aragonesa.

No tengo aquí la pretensión de plantear de nuevo una constatación muchas veces realizada. Pero creo que no se puede uno quedar con esas visiones generales, que han sido sugeridas, en su conjunto, por textos de carácter normativo. Es importante llevar adelante estudios más detallados, que deberían permitir, al mismo tiempo, hacer surgir matices inter-regionales, subrayar una o varias evoluciones --pues ¿cómo imaginar que la situación en 1609 haya sido idéntica a la de 1500 o de 1525?--, mostrar toda la riqueza de una gama que iría desde el morisco estrictamente monolingüe al morisco perfectamente bilingüe, revelar finalmente la complejidad de los intercambios lingüisticos entre cristianos viejos y nuevos. Esto es tanto más pertinente cuanto que, por una parte, "l'Islam, bien que basé sur la prééminence religieuse de l'arabe, admet parfaitement l'usage d'autres langues de toute origine", y que, por otra parte, las innumerables acciones que apuntaban a eliminar la lengua árabe del territorio español en el siglo XVI no fueron, finalmente, más que amenazas sin efecto consiguiente.

No me detendré ni sobre los aragoneses, ni sobre los castellanos. Con todo, algunas advertencias me parecen necesarias. Louis Cardaillac cita el pasaje elocuente de un tratado que Muhámmad Devera escribió, poco antes de la expulsión, dirigido a sus correligionarios aragoneses. Según ese documento, a los moriscos aragoneses les faltaría "science et

${ }^{7}$ Ver, por ejemplo, Francisco de Borja de Medina, "La Compañía de Jesús y la minoría morisca (1545-1614)", Archivum Historicum Societatis lesu, Roma, vol. LVII, 1988, p. 53.

${ }^{8}$ Míkel de Epalza, "L'identité onomastique et linguistique des morisques", Religion, ldentité et Sources Documentaires sur les Morisques Andalous, ed. Abdeljelil Temimi, Túnez, 1984, tomo I, p. 278. 
bons jugements, non par manque de foi mais pour avoir perdu l'usage de la langue arabe" ${ }^{\prime 9}$. Otros testimonios indican que algunos aragoneses dirigían a sus hijos a valencianos, para que fueran instruidos en la lengua coránica, prueba de la falta de tales enseñanzas en el valle del Ebro. Pero ¿puede generalizarse? Estudiando la posesión del libro en la comunidad morisca aragonesa, Jacqueline Fournel-Guérin constata que "le maçon Gabriel Peax a neuf livres en arabe qu'il sait lire et que le notaire de Roden, Lope de Monte, apprit l'arabe avec son père"10. Entre 1568 y 1609, 406 personas son condenadas por la Inquisición de Zaragoza, por haber conservado escritos: entre ellas hay maestros de escuela, médicos, notarios, labradores, sastres, etc. "La plupart d'entre eux --según afirma ella--sont des gens aisés qui savent lire et écrire l'arabe" 11 .

Esta conclusión no es nada segura, ya que la equivalencia entre posesión de un libro en árabe y dominio de la lengua no es en manera alguna evidente, pero la misma autora da varios ejemplos de existencia de escuelas coránicas. Una verdadera red de venta de libros, sobre todo de Coranes, funcionaba durante el último tercio del siglo XVI. ¿Eran esfuerzos desesperados para mantener una llama vacilante o era una bolsa de resistencia en un universo mayoritariamente aculturado? El tema aragonés no está, en manera alguna, cerrado.

Las mismas observaciones pueden hacerse a propósito de los moriscos castellanos y navarros. No hay duda de que el largo espacio de tiempo de la dominación cristiana --como sucedió en Aragón-- y la disolución de las comunidades moriscas han provocado una evolución irremediable. Pero se pueden encontrar, aquí y allá, algunas notas discordantes. En Murcia, en abril de 1571 , se celebra un sínodo que recomienda la dispersión de los minoritarios, para que olviden "leur

${ }^{9}$ Louis Cardaillac, Morisques et chrétiens, un affrontement polémique (14921640), París, 1977, p. 154.

10 Jacqueline Fournel-Guérin, "Le livre et la civilisation écrite dans la communauté morisque aragonaise (1540-1620)", Mélanges de la Casa de Velázquez, Madrid, 1979, pp. 243 et 245.

11 Ibid., p. 243. 
mauvaise langue arabe"12. En Hornachos, en Extremadura, hay habitantes que enseñan el árabe ${ }^{13}$. Mercedes Garcfa Arenal destaca que, en Navarra, el uso del árabe hablado y escrito se mantuvo relativamente bien hasta principios del siglo $\mathrm{XVI}^{14}$. Quizás no se trate aquí más que de fenómenos excepcionales, pero nos invitan a ser circunspectos, a la prudencia y al trabajo. Y sobre todo a preguntarnos -lo que nadie ha hecho todavía-- por las consecuencias, en materia lingǘstica, de la deportación de los granadinos arabizados en el conjunto de Castilla, de Extremadura y de Andalucía occidental. En Villanueva de la Jara, en los límites de la Mancha, en 1581, los moriscos saben recitar en castellano oraciones, credo y los diez mandamientos ${ }^{15}$. Eso, con gran satisfacción del sacerdote local. Pero una vez la lección bien recitada, una vez de vuelta a sus casas, ¿qué lengua hablaban?

De todas formas, se está aquí muy lejos de la situación de los valencianos y de los granadinos hasta 1570. Estos dos grandes grupos han constituido más de los dos tercios de la "nación" morisca. En su seno, la lengua árabe ha perdurado. Y la cuestion que aquí se plantea no es la de que quién se expresaba en árabe, sino más bien de que quién se expresaba en lengua romance, castellano o "valenciano". Las autoridades civiles y eclesiásticas no dejan de destacar lo que separa profundamente a hombres y mujeres en esta materia. Cuatro ejemplos. Ya en un informe de 1528, se dice que "en el dicho reyno [de Valencia] la mayor parte de los moros y casi todas las moras no saben hablar aljamía". El texto de noviembre de 1566 , que se refiere al reino de Granada, afirma: "Ios más dellos [moriscos], especialmente mujeres y niños, no entendían nuestra lengua". Las autoridades municipales de Córdoba, que habían acogido a los moriscos deportados, retoman casi

12 Juan Bautista Vilar, "L'Inquisition de Murcie", Les Morisques et l'inquisition, ed. L. Cardaillac, París, 1990, p. 253.

13 Julio Fernández Nieva, "L'Inquisition de Llerena", Les Morisques et l'inquisition, op. cit., p. 272.

${ }^{14}$ Mercedes García Arenal y Béatrice Leroy, Moros y judios en Navarra en la baja edad media, Madrid, 1984, p. 38.

15 A.G.S., Cámara de Castilla, legajo 2183, s.f. 
con los mismos términos la misma constatación: los hombres de más edad, las mujeres y los niños ignoran el castellano ${ }^{16}$. La constatación es idéntica para el reino de Valencia. En 1595, el obispo de Orihuela, enumerando los obstáculos para una buena catequesis, pone en primer lugar el hecho de que "las mugeres [son] tan obstinadas y tan adversas a nuestro lenguaje"17. Está claro que las mujeres moriscas, al tener menos contactos que sus maridos o sus hermanos con los cristianos viejos, han tenido un papel esencial en la conservación de la lengua árabe. Ésta es la lengua del hogar. Por tanto, todos la practican y la mantienen.

Pero, una vez más, detrás de estas afirmaciones generales, que no plantean duda alguna, se esconden realidades movedizas que tenemos que descubrir gracias a la ayuda de las fuentes inquisitoriales, notariales o municipales. Hay documentos bastante numerosos que indican la presencia necesaria de un intérprete. Ya Carmen Barceló y Ana Labarta han proporcionado algunos testimonios de ello ${ }^{18}$. Así, de las 11 mujeres que aparecen en los procesos de habitantes de la Valldigna entre 1601 y 1605,7 necesitan intérprete ${ }^{19}$. Tenemos, para tres pueblos de la huerta valenciana (Carlet, Benimodo y Benismuslem), en 1574, una muestra bastante más amplia, ya que se basa en 569 personas, de las que la más joven tiene 11 años $^{20}$. Son interrogados uno por uno sobre sus prácticas musulmanas por el inquisidor, con ocasión de un edicto de gracia. Nos encontramos con 310 mujeres y 259 hombres. Pues bien, si 250 de estos últimos no necesitan truchimán,

${ }^{16}$ Archivo Municipal de Córdoba, libros de actas, año 1572. El texto ha sido publicado por Florencio Janer, Condición social de los moriscos de España, Madrid, 1857, pp. 256-257 (nueva edición, Barcelona, 1987).

${ }^{17}$ P. Boronat y Barrachina, op. cit., tomo I, p. 653.

18 Por ejemplo, en Ana Labarta, "Inventario de los documentos árabes contenidos en procesos inquisitoriales, contra moriscos valencianos, conservados en el Archivo Histórico Nacional de Madrid (Legajos 548-556)", Al-Qantara, Madrid, I, 1980, pp. 115-164, y en María del Carmen Barceló Torres, Minorias islámicas en el País Valenciano. Historia y Dialecto, Valencia, 1984.

${ }^{19}$ María del Carmen Barceló Torres, op. cit., p. 141.

20 Archivo Histórico Nacional de Madrid (A.H.N.), sección Inquisición, legajo 556-22; legajo 803-2; y documento proveniente de una colección particular. 
sólo 26 mujeres no tienen esa ayuda. La división no puede ser más neta, ni más elocuente.

De todas formas, las cifras globales desdibujan matices importantes. La diferencia está clara entre las tres comunidades. Benismuslem no tiene más que 100 a 120 habitantes, todos moriscos, mientras que Benimodo, igualmente homogéneo, se acerca a los 300 habitantes, y Carlet, pueblo grande de alrededor de un millar de habitantes, tiene una cuarta parte de cristianos viejos. Los moriscos de Benismuslem, hombres y mujeres, son todos capaces de responder en lengua romance a las cuestiones de los inquisidores, mientras que las mujeres de Benimodo y de Carlet, con seis excepciones, tres para cada pueblo, son impermeables (éstas tienen menos de 40 años). Los hombres, al contrario, son aljamiados, salvo nueve, todos habitantes de Benimodo. Estos datos permiten un montón de observaciones. La más pequeña de las tres comunidades está aculturada. ¿Hay que pensar que hubo aquí una catequesis continua y eficaz, mientras que en Carlet los efectos de la convivencia apenas se dejan sentir y que Benimodo es el ejemplo mismo de la resistencia lingüística? Las causas de las diferencias entre comunidades separadas por poca distancia no son fáciles de dilucidar, pero lo que es importante, por ahora, es destacar tres situaciones que no son idénticas. De esta forma se abren perspectivas de investigación más minuciosas, aunque este asunto es excepcional, por ahora.

En efecto, no he encontrado nada parecido en otros sitios. Para el reino de Granada, tengo que contentarme con sondeos cuantitativamente más pobres y, sobre todo, donde las mujeres están ausentes. A falta de más datos, hay que admitir la práctica exclusiva del árabe para la casi totalidad de ellas. Una pequeña prueba suplementaria confirmaría esta afirmación: Isabel Medana, viuda del labrador Francisco Abuhamin y habitante de Dilar, pueblo de la vega de Granada, es una de las pocas moriscas que hace un testamento ante un notario cristiano viejo ${ }^{21}$. Pues bien, llama a un intérprete. Para los hombres, ya es muy llamativo el que, cuando la reunion, en 1558 , de 82 prohombres de las Alpujarras (a razón de dos representantes por pueblo de realengo), la intervención

${ }^{21}$ Archivo Notarial de Granada, 2.1.3., 1568. 
de Hernán Gutiérrez, intérprete, haya sido indispensable ${ }^{22}$. Por tanto, entre esos hombres que tenían todos responsabilidades, de alguacil o regidor, y que por ello tenían múltiples ocasiones de intercambio con cristianos viejos, una parte al menos ignoraba enteramente la lengua castellana. Entre los 82 presentes figuran la mayor parte de los futuros líderes de la sublevación de la región en 1568: Hernando el Zaguer, del pueblo de Cadiar; Miguel de Rojas y Lorenzo de Arcos, de Uǵjar; Hernando el Dendena, de Paterna; etc. Dos otras pequeñas muestras. En Purchena, en el valle del Almanzora, al noroeste del reino de Granada, se abre una encuesta, en 1562, como consecuencia de unas inundaciones ${ }^{23}$. Las autoridades, queriendo evaluar los daños, interrogan a diez testigos moriscos. Cinco son aljamiados y cinco se expresan en lengua árabe. No lejos de allí, en Vera, año tras año, se firman los contratos de arrendamiento de pastos reservados para rebaños trashumantes. Se indican a veces --no siempre, por desgracia-- si los propietarios de ganado y sus garantes han sido o no capaces de hacer una declaración en castellano. He recogido 41 casos entre $1554 \mathrm{y}$ $1562^{24}$. 16 personas son aljamiadas, 25 no lo son. ¿Corresponde esta proporción a una lógica clara? No lo parece, a primera vista, y es seguro que no hay matiz geográfico preciso. Los unos y los otros pertenecen a los mismos pueblos de la región de Baza, del marquesado del Cenete, de la sierra de Filabres y de los pueblos cercanos a Vera. La impresión que se saca de estos elementos dispersos es que la lengua castellana ha penetrado con bastante dificultad las zonas rurales moriscas, pero que, aquí y allá, siempre se encontrarán algunos individuos que servirán de intermediarios.

Si el dimorfismo sexual está bien documentado, muchas sombras permanecen. ¿Existen otros criterios de diferenciación al interior de las comunidades moriscas? Hay que pensar en particular a posibles diferencias de orden social o socio-profesional. Si el ejemplo de los notables de las Alpujarras es pertinente a una escala más amplia, la élite rural habría estado poco aculturada, apenas más que el conjunto del

\footnotetext{
22 Ibid., escribanía Melchor de Alcocer, 1558, fol. 768.

23 A.G.S., Expedientes de Hacienda, legajo 146.

${ }^{24}$ Archivo Municipal de Vera (A.M.V.), legajo 953.
} 
mundo rural morisco. Pero esto está por probar. ¿Y qué se puede decir de las élites urbanas, principalmente granadinas? ¿Se puede sacar de ellas estrategias de integración, fomentadas por las autoridades que, en parte, pasaran por la vía lingüística? Es probable que los Zegrí, Granada Venegas, López Caybona, Palacios..., todos ellos ostentadores de cargos municipales o fiscales, fueran perfectamente bilingües ${ }^{25}$. El hecho es patente para los que sirven de intérpretes oficiales a la municipalidad (son en permanencia cuatro en Granada), a la Inquisición y a otras instituciones, como Garcfa Chacón o Zacarías de Mendoza, que vemos intervenir en muchos $\operatorname{casos}^{26}$. Dos de ellos, Alonso del Castillo y Miguel de Luna, se hicieron famosos al servicio de Felipe II $^{27}$. De hecho, para estudiar la minoría morisca, la cuestión linguística tiene que plantearse en términos enteramente nuevos. Los pocos trabajos que se han consagrado a este problema lo han abordado casi siempre en el marco del todo o nada, en un enfrentamiento radical entre lenguas inalterables e irreductibles, árabe contra castellano o catalán. La realidad, hecha de intercambios diarios, de préstamos y de erosiones, es muy diferente. Entre el monolingüismo absoluto arabófono y el dominio perfecto del bilingüismo, hay sitio para un montón de grados lingüísticos, como bien se sabe en nuestras sociedades contemporáneas. ¿Por qué no sería lo mismo en la España del siglo XVI? Las relaciones de vecindad, las necesidades del trabajo y del mercado, las desiguales modalidades de la evangelización, según los lugares y los períodos, han dejado cada una su huella. Hay que reconocer que no es fácil descubrir estas situaciones intermedias, bilingüismos asimétricos y bilingüismos de intelección, cuando son los más frecuentes, pero esto no es disculpa para renunciar a buscarlos ${ }^{28}$.

25 Ver Bernard Vincent, Andalucía en la edad moderna: economía y sociedad, pp. 105 y 274-278.

${ }^{26}$ Para García Chacón, A.H.N de Madrid, Inquisición, legajo 2604; para Zacarías de Mendoza, Archivo de la Alhambra, legajo 64-23 y referencia de la nota 21 .

${ }^{27}$ Darío Cabanelas Rodríguez, El morisco granadino Alonso del Castillo, Granada, 1965.

${ }^{28}$ Jalil Bennani et alii, Du bilinguisme, París, 1985. 
Quedan algunas huellas de estos bilingüismos. El Padre Darfo Cabanelas ha publicado recientemente una inscripción árabe encontrada en el Albaicín de Granada y fechada, con mucha verosimilitud, de la segunda mitad del siglo $\mathrm{XV}^{29}$. La forma de muchas palabras es incorrecta, con consonantes elididas, concordancias defectuosas... A la vista de este documento y de otros indicios, el P. Cabanelas saca la conclusión de que no sólo los moriscos perdían progresivamente la hermosa caligrafía árabe, sino también una expresión fonética correcta y el dominio de la gramática del árabe literal. Esta constatación nos lleva a una serie de interrogaciones sobre los medios de la transmisión de la lengua árabe en el seno de la comunidad morisca. Ya se ha aludido a las escuelas coránicas aragonesas. Existía una en Calanda hacia 1580 , a la que asistían dos hermanos, Jerónimo y Juan Sifuentes, que tenfan 22 y 24 años. Otra, por la misma época, estaba situada en Almonacid de la Sierra. Había también éscuelas, evidentemente, en el reino de Valencia. Rafael Carrasco afirma que las reuniones con predicaciones y lecturas colectivas, las escuelas para niños y las consultas de alfaquies estaban organizadas desde cada aljama ${ }^{30}$. Con ocasión de interrogatorios inquisitoriales, los moriscos mencionan a menudo escuelas donde 50 o 60 jóvenes de 12 a 25 años eran reunidos para aprender de un maestro tanto el árabe como la ley islámica ${ }^{31}$. Boronat proporciona varios ejemplos de alfaquíes de la región de Segorbe (Adzaneta, Alfandeguilla, Coneja, Fanzara, etc.), que enseñaban el árabe, hacia $1560^{32}$. Me inclinaŕa a creer que habría una red semejante al interior del reino de Granada, pero en este último caso, por falta de procesos inquisitoriales, la documentación está por

29 Darío Cabanelas Rodríguez, "Una inscripción morisca del Albaicín", Cuadernos de la Alhambra, Granada, XXII, 1986, pp. 95-99.

${ }^{30}$ Rafael Carrasco, "Le refus d'assimilation des Morisques: aspects politiques et culturels d'après les sources inquisitoriales", Les Morisques et leur temps, ed. L. Cardaillac, París, 1983, p, 192.

31 Ibid., p. 205.

${ }^{32}$ P. Boronat y Barrachina, op. cit., tomo I, pp. 541-542. 
inventar. En cambio, la lectura atenta de los casos juzgados por los tribunales de Zaragoza y de Valencia darfa ciertamente resultados. Eso no empece que, fuera de ambientes muy homogéneos, el aprendizaje del árabe no debía de ser cosa fácil. La población morisca era ampliamente analfabeta. Estudiando los 172 procesos de moriscos que dependían de la Inquisición de Valencia, Ana Labarta y Rafael Carrasco llegan a las mismas conclusiones. Los hombres son analfabetos en un $72 \%$, según la primera, para quien este porcentaje está infravalorado, por la personalidad de los acusados ${ }^{33} .11$ de los 125 hombres acusados firman en árabe, según el segundo ${ }^{34}$. Retomando el sondeo referido a Benimodo, Benismuslem y Carlet, constato que los 246 hombres $(80+14+$ 152) de los que tenemos o una firma o la mención no sabe escribir, sólo 18 son capaces de firmar. El detalle no carece de interés. 10 habitantes de Carlet se codean en este palmarés con otros seis de Benimodo y uno solo de Benismuslem.

Por tanto, el porcentaje global de capaces de leer es de un 7'3\%. $Y$ si se tiene en cuenta a las mujeres --ninguna de ellas sabe firmar--, el porcentaje baja al 3'3 \%. Se puede así apreciar toda la dificultad que suponía la transmisión de una parte esencial de la cultura musulmana. Sólo algunos hombres son capaces de asegurar el aprendizaje de la lectura o de leer en una velada. Y, además, ¿cuál era su grado de dominio del árabe? Obligatoriamente muy solicitados, se les puede detectar más fácilmente y constituyen un blanco ideal para la Inquisición, que se preocupa mucho de los que hacen proselitismo. El peligro es además considerable, porque los que son capaces de leer son ancianos. El más joven tendría 30 años, otro 34, un tercero 36 años. Dos son cuarentones ( 41 y 46 años), tres cincuentones (dos veces 50 años y uno 56), cinco sesentones, tres de más de 70 años, con uno de 86 años que les acompaña. La renovación de los indispensables intermediarios culturales no parece estar asegurada. Un buen conocimiento de los libros, principalmente del Corán, que no sea sólo

33 A. Labarta, op. cit., p. 115.

${ }^{34}$ Agradezco a Rafael Carrasco, que me ha comunicado los resultados de su encuesta. Ver igualmente R. Carrasco, "Historia de una represión. Los moriscos y la inquisición en Valencia, 1566-1620", Areas, Murcia, n 9, 1988, pp. 27-50, particularmente pp. 39-40. 
memorizado, se ve condenado a desaparecer, a corto plazo. Notemos todavía más la fragilidad diferencial de las comunidades. Benismuslem, con un solo lector de 60 años, se encuentra en una situación dramática. En Benimodo, con siete lectores entre 80 hombres, las posibilidades son más amplias, mientras que Carlet --diez posibles lectores para 152 hombres-- ofrece un perfil medio. Es verdad que estamos razonando con un muestrario escaso, pero las diferencias que aqui se registran confirman las que hemos percibido antes, a propósito de la necesidad de intérprete. El test parece, pues, válido, aunque cierta duda permanece en cuanto a la sinceridad de los declarantes. ¿No tenían quizás interés, sobre todo los más jóvenes, en esconder sus capacidades de leer y escribir en árabe? De todas formas, la evolución que sugieren estos pocos testimonios precedentes me hacen pensar irresistiblemente en una reducción progresiva y rápida de la capacidad de lectura en árabe.

Preguntas semejantes se plantean en cuanto a la noción de aljamiado. El término, cuando califica a un morisco, tiene dos acepciones. Una muy general, que designa al individuo desprovisto de todo signo exterior que revelaría su pertenencia a la comunidad minoritaria. Otra, más restringida, que es la que nos interesa aquí, subraya la aculturación linguística. Pero ¿qué se sabe, en realidad, de las capacidades de expresión y de comunicación de los moriscos en lengua castellana o valenciana? Prácticamente nada. Un texto de $\mathbf{1 5 4 5}$, con ocasión de un proceso entre las localidades de Vera, Sorbas y Lubrín, al noroeste del reino de Granada, nos coloca en el camino que hay que seguir ${ }^{35}$. Los testigos moriscos del asunto se ven en fin de cuentas apartados, porque cualquiera de ellos "puede saber una palabra de aljamía e otra no, de las que el interrogatorio declara, e por entender una cosa dirá otra...". ¿A partir de qué momento los cristianos viejos determinan que un morisco es aljamiado? ¿Cuando posee perfectamente la lengua, cuando es capaz de hacerse entender o cuando balbucea algunas palabras? Se puede apostar con certeza que las dos últimas eventualidades eran más frecuentes que la primera.

Los moriscos del reino de Valencia se veían confrontados con una dificultad suplementaria, resultado del uso paralelo del valenciano y del

${ }^{35}$ A.M.V., legajo 438-8. 
castellano en la región. En los textos oficiales publicados por Pascual Boronat y analizados por Joan Fuster, siempre se trata de las dos lenguas románicas, puestas así en un mismo pie de igualdad ${ }^{36}$. Ya en 1528, Carlos $\mathrm{V}$ concedía a los moriscos valencianos una moratoria de diez años para "aprender aljamfa o romance castellano o valenciano" ${ }^{37}$. En un memorial de los síndicos de las aljamas, fechado de 1595, se recuerda que la mayor parte de los cristianos nuevos no comprenden ni el valenciano, ni el castellano ${ }^{38}$. Cuando se entra en el detalle de los hechos, se da uno cuenta de que en el contacto de los cristianos viejos, Eça, alfaquí de Fansara en los años 1560, lee y escribe en castellano, según se afirma ${ }^{39}$. En Carlet, Isabel Comixi es interrogada en presencia del intérprete, aunque sabe el castellano ${ }^{40}$. María Aldamis, morisca de Xaraguel, condenada por la Inquisición en 1602, recita el Pater y el Ave Marfa en "romance castellano" ${ }^{41}$. Pero por el contrario, otras dos victimas del tribunal, Marfa Casay que vive cerca de Cocentaina, en 1606, y Gaspar Febrer, habitante de Benissa, en 1608, se expresan en valenciano $^{42}$. La primera recita el Pater, el Ave y el Credo, el segundo el Pater, Ave, Salve, Credo y los diez mandamientos. Estas indicaciones no son una prueba del conocimiento de una u otra de las lenguas romances, pero al menos suponen una enseñanza puntual recibida. Me guardaré bien de sacar la menor conclusión en materia tan delicada. Sólo constato que la situación es fluctuante y que hay aquí un campo que desbrozar. La lógica exigiría que los moriscos hubieran adquirido rudimentos (o más) de la lengua de sus vecinos cristianos viejos. Éstos

36 Juan Fuster, Poetas, moriscos y curas, Madrid, 1969. Ver también el análisis sugerente de Dolors Bramón, Contra moros i jueus, Valencia, 1981 (versión en castellano, Barcelona, 1986).

${ }^{37}$ P. Boronat y Barrachina, op. cit., p. 424.

${ }^{38}$ Archivo del Ministerio de Asuntos Exteriores de Madrid, relaciones con la Santa-Sede, legajo 23, fol. 76; documento publicado por P. Boronat, op. cit., tomo II, p. 714 .

39 Ver nota 32.

${ }^{40}$ A.H.N., sección Inquisición, legajo 556-22, fol. 133.

${ }^{41}$ Ibid., legajo 550-11.

42 lbid., legajos 550-8 y 551-10. Estas indicaciones, como la anterior, me han sido proporcionadas por Rafael Carrasco. 
en su inmensa mayoría pertenecían al mundo rural de lengua catalana. La comprehensión del castellano en Fansara o Carlet es un problema. La hipótesis la más verosímil es la siguiente: la acción del clero, que tiene al castellano como lengua vehicular privilegiada, ha hecho retroceder el uso del valenciano entre los moriscos. Tendríamos aquí uno de los resultados de la ofensiva oficial en favor del castellano en el siglo $\mathrm{XVI}^{43}$. Por supuesto que sólo un análisis micro-regional comparativo entre el XV --cuando la evangelización no había empezado-- y el XVI permitirá aprehender la amplitud del fenómeno. ¿Es posible?

$$
* * *
$$

En las páginas anteriores, he intentado mostrar cómo, en el seno de la comunidad morisca, podemos encontrar una gama muy amplia de perfiles lingüísticos. Pero tampoco se puede obviar el trámite inverso. ¿Cómo y en qué medida el árabe ha penetrado en la sociedad dominante? Esta cuestion, como otras, no ha sido planteada, al menos para el período que nos ocupa. ¿Cómo, en efecto, imaginar que algunos raros cristianos, inmersos en un ambiente morisco, no hayan sido permeables a la lengua localmente más practicada? Sólo, que yo sepa, Carmen Barcelo, en su hermoso libro, ha puesto algunos útiles jalones ${ }^{44}$. Así es como numerosos señores valencianos comprendían o hablaban el árabe, como por ejemplo Gisbert Doms de Bonastre, señor de Relleu a principios del siglo XVI, o Ximén Rois de Corella, conde de Cocentaina hacia 1570. Otros, de clase más modesta, como el cristiano viejo de Matet, que habría descubierto una conspiración en 1596, o como Francisco Bucas, servidor del notable morisco Cosme de Abenamir, han aprendido por la práctica un idioma que les era desconocido ${ }^{45}$.

Tenemos el mismo escenario en el reino de Granada. Hay tanto cristianos viejos como moriscos, que sirven de intérpretes con ocasión

${ }^{43}$ Sobre esta importante cuestión, además de la obra de Joan Fuster citada en la nota 36, ver Ricardo García Cárcel, Herejía y sociedad en el siglo XVI. La inquisición en Valencia 1530-1609, Barcelona, 1980, pp. 312-320.

${ }^{44}$ María del Carmen Barceló, op. cit., pp. 136-151.

45 Ibid., p. 145. 
de la firma de contratos o de procesos. Así en Vera, Alonso de Caparrós, Miguel Rodríguez, el jurado Martín de Salas, Francisco González, arrendador de las rentas eclesiásticas, y Juan Ortiz, mayordomo de la municipalidad, realizan muchas veces esta función, cuando negocian los contratos entre la municipalidad y propietarios de rebaños trashumantes ${ }^{46}$. En 1529, en Almería, en el momento de la redaccion de un testamento, el notario quiere precisar que comprende la lengua árabe. En 1561, en Benahaduz, pueblo cercano a Almería, el intérprete del testamento de Diego y María Zupil es el sacristán ${ }^{47}$. En el mismo año, en Guajar Alta, ni un solo morisco del lugar era capaz de servir de truchimán y hay que llamar a Francisco de Bustillo, cristiano viejo de Salobreña ${ }^{48}$. El cronista Mármol Carvajal cuenta que en los primeros días de 1569 , un soldado originario de Orjiva, Juan Lopez, consiguió suministrar armas a los cristianos sitiados en la iglesia "aprovechándose de la lengua árabe, en que era muy ladino"49. Finalmente, en 1573, es otra vez un sacristán el que, en Felix, sirve de intermediario entre los comisarios encargados del repoblamiento y los moriscos "conocedores de los lugares"50. Por todas partes, las necesidades de la vida cotidiana, de la convivencia, incitan a los préstamos lingüísticos de la lengua del Otro.

Hay también eclesiásticos que conocen el árabe. A lo largo del siglo XVI y hasta la expulsión de 1609 , se ha desarrollado un debate sobre las modalidades de la evangelización. Ciertamente, la gran mayoría del clero, siguiendo la posición oficial, piensa que hay que erradicar la lengua árabe, que no es apta, según dicen, para expresar los misterios de la verdadera fe y es, por el contrario, propagadora de la fe musulmana. Pero existe permanentemente una corriente favorable a una catequesis en la lengua de los minoritarios. Por razones de realismo y de eficacia. Uno de sus iniciadores fue Fray Hernando de Talavera,

46 Ver nota 24.

${ }^{47}$ Nicolás Cabrillana, Almería morisca, Granada, 1982, p. 32. Esta obra está llena de referencias lingüísticas, por ejemplo pp. 30, 31, 34-35, 69-71, 75-78.

48 A.G.S., Expedientes de Hacienda, legajo 131.

49 Luis de Mármol, op. cit., p. 228.

${ }^{50}$ Archivo Municipal de Felix, libro de apeo. 
el primer arzobispo de Granada. Según uno de sus familiares, "hizo buscar de diversas partes sacerdotes, así religiosos como clérigos, que supiesen la lengua arábiga; e aś fizo en su casa pública escuela de arábigo en que la enseñasen; y él, con toda su tanta edad y experiencia y diligencia, se abajaba a oir y aprender los primeros nomativos, y así aprendió algunos vocablos...". También obraban así inquisidores y obispos, como Martín García, que predicaba en Granada, en árabe, ya en 1500, antes de ser archidiácono de Daroca y luego inquisidor, o como Martín Pérez de Ayala, obispo de Guadix y luego arzobispo de Granada, que incitaba a la utilización de la lengua árabe. Se encuentra un eco de esta corriente en las recomendaciones hechas al clero del obispado de Granada en los años 1500 . "El cura o beneficiado que no supiere la lengua arábiga no confiese a ninguno que no supiere aljamía, sino solamente aquellas personas que él entendiere que le podrán entender", según se precisa ${ }^{\text {s1 }}$. Hay también religiosos, más particularmente franciscanos como Antonio Sobrino y Jerónimo de Corella, y jesuitas. Éstos últimos merecen aqứ una mención particular, ya que la enseñanza en árabe ha sido una de las piedras angulares de su acción en el medio morisco. Recuerdan constantemente la necesidad de hacerse comprender. El rector del colegio de Gandía, en los años 1560, echaba de menos, con toda su alma, una predicación en árabe. El viceprovincial de Aragón, en 1565, segúa sus trazas y recibía el apoyo de Carlos Borja, duque de Gandía ${ }^{52}$. Se confía particularmente en el apostolado de moriscos que han sido admitidos en la Compaña. Dos de ellos son muy célebres. Se trata, por una parte, de Juan de Albotodo, nacido en 1527 en Granada, el cual, después de haber realizado estudios en el colegio San Miguel, ejerció su ministerio en la colina del Albaicín y en las prisiones de la ciudad, y, por otra parte, de Ignacio de Las Casas, el cual, nacido en Granada en 1550, se entrego al apostolado con los moriscos, totalmente y toda su vida, desde su entrada en la Compañía en 1572 hasta su muerte en $1608^{53}$. Fue destinado a p. 61 .

${ }^{51}$ Brígido Ponce de León, Historia de Alhendín de la Vega, Madrid, 1960,

${ }^{52}$ Francisco de Borja Medina, op. cit., pp. 38-40.

${ }^{53}$ Para Albotodo y el colegio de los jesuitas de Granada, ver Antonio Garrido 
numerosos colegios (Valencia, Segovia, Ávila, Granada,...) y fue promotor de una academia de lengua árabe (1604). Pero este último proyecto fracasó. A éstos se puede añadir Francisco Hernández, nacido en 1544 en Fortuna (Murcia) y muerto prematuramente en 1570. Jerónimo de Mur, nacido en 1525 en Bechr (Castellon), aunque su origen morisco no se ha podido probar ${ }^{54}$. Eso no empece que su obra ilustra bien los esfuerzos de los jesuitas. Entre 1565 a 1602, se consagró al mundo morisco valenciano, descontando un perfodo de cinco años (1567-1572) en que permaneció en Orán. Dejó un vocabulario árabe casi terminado.

De esta forma, se ve que, por múltiples causas, el árabe estaba más difundido de lo que parece, en la sociedad cristiana. O al menos en las regiones que tenían una concentración morisca. Este aspecto ha sido demasiado descuidado. Su realidad complica aún más una situación singularmente confusa. En efecto, los castellanofonos y los catalanofonos tomaban préstamos del árabe de España, precisamente cuando éste se degradaba. El concepto de islam affaibli ("islam debilitado") que ha sacado a relucir Leila Sabbagh, se aplica perfectamente a la lengua utilizada por los moriscos en el giro de los siglos XVI y XVII ${ }^{55}$. Los interesados no midieron probablemente la amplitud de la degradación hasta que se vieron en el exilio en 1609 , pero sin duda ya tendrían algo de conciencia de ello antes. Así, haciéndose eco del aviso de Aben Daud, se agarraban a ese signo identitario capital y buscaban desesperadamente el conservarlo. Pero en el campo cristiano, después de 1570, se alzaban, cada vez más atronadoras, voces que reclamaban remedios expeditivos. Se conoce las posiciones extremas del arzobispo de Valencia, Juan de Ribera, y la nota, sugiriendo la prohibición de la lengua árabe, remitida por el dominico Luis Beltrán, en 1579, al duque de Nájera, virrey. Se conoce menos el contenido de dos arbitrios, tan elocuentes, redactados este mismo año. (¿Hay que creer que hab́a una

Aranda, Moriscos e indios, México, 1980. B. Vincent, Minorías y marginados en la España del siglo XVI, Granada, 1987, pp. 101-118. Y sobre todo Francisco de Borja Medina, op. cit.

${ }^{54}$ Francisco de Borja Medina, op. cit., pp. 37 y 117.

s5 Leila Sabbagh, "La religion des Morisques entre deux fatwas", Les Morisques et leur temps, op. cit., pp. 45-56. 
campaña orquestada?). En uno, Diego Ordoñez, antiguo capellán de la reina Leonor, hermana de Carlos V y esposa de Francisco I, afirma que la maldita "secta" perdurará mientras que la lengua "mahometista" (iqué simplismo!) sea empleada. Por eso propone que los niños moriscos sean arrancados de sus madres "para que no aprendiesen la lengua morisca, sino la castellana, y fuesen criados a costa de sus padres, si tuviesen de qué, y si no, que de limosna de los pueblos a donde estuviesen, se criasen". Por otra parte, Diego de Osaguera, miembro del entorno de Felipe II --era contino-- aconseja sencillamente reducir en esclavitud los niños moriscos ${ }^{56}$. Este estruendo acabó por llevarse todo a su paso, aislando y desanimando a los que exploraban caminos más o menos sincréticos, imponiendo una visión simplista y reductora de una realidad rica y movediza ${ }^{57}$.

${ }^{56}$ Los dos documentos figuran en el Archivo General de Simancas, Cámara de Castilla, legajo 2.180.

57 Una primera versión de este trabajo en francés e incompleta ha aparecido en Proyección histórica de España en sus tres culturas: Castilla y León, América y el Mediterráneo, Valladolid, 1993, tomo I, pp. 369-378. Después de su publicación, vio la luz el importante artículo de Eugenio Císcar Pallarés " "Algaravía» y «algemía». Precisiones sobre la lengua de los moriscos en el Reino de Valencia", al-Qantara, 1994, pp. 131-162. Sus conclusiones sobre el amplio bilingüismo de los moriscos, particularmente de los hombres, y sobre los conocimientos del árabe por un sector de la sociedad cristiana en la zona de Valldigna van en el mismo sentido que mi estudio. 